\title{
REDUÇÃO DA TAXA DE EXPANSÃO FOLIAR DE TOMATEIROS PARASITADOS POR Meloidogyne javanica
}

BELAN, Leônidas Leoni ${ }^{1}$ ALVES, Fábio Ramos ${ }^{2}$

JESUS JUNIOR, Waldir Cintra de ${ }^{3}$

\begin{abstract}
RESUMO: Entre os problemas que mais afetam a produção do tomateiro estão os fitopatógenos. Dentre esses, os nematoides do gênero Meloidogyne causam consideráveis perdas econômicas anuais no cultivo de tomate em todo o mundo. O conhecimento dos índices fisiológicos de crescimento é extremamente importante na interpretação das relações patógeno-hospedeiro-ambiente. Neste contexto, quantificou-se a influência do parasitismo de populações crescentes de $M$. javanica (Treub) sobre a taxa expansão da área foliar (TEAF) na fase de desenvolvimento inicial de acessos de tomateiro tipo cereja. Os efeitos negativos do parasitismo dos nematoides se manifestaram na fase inicial de desenvolvimento das plantas. Verificou-se crescimento linear da população final $(\mathrm{PF})$ de $M$. javanica em todos os acessos de tomateiro cereja avaliados à medida que se aumentou o nível do inóculo inicial do nematoide, ocasionando redução linear da TEAF. Dessa forma, práticas de manejo que reduzam a população de nematoides do solo durante a fase vegetativa dos tomateiros, poderão favorecer o crescimento e desenvolvimento das plantas e a consequente produção de frutos.
\end{abstract}

Palavras Chave: Solanum lycopersicum. Nematoide das galhas. Área foliar. Danos

\section{REDUCTION IN LEAF EXPANSION RATE ON TOMATO PLANTS PARASITIZED BY Meloidogyne javanica}

\begin{abstract}
SUMMARY: Among the problems affecting tomato production phytopatogens are the most important. Among these, nematodes of the genus Meloidogyne cause large annual economic yield losses in tomato cultivation around the world. The knowledge of the physiological indices of growth is extremely important in the interpretation of pathogen-host-environment relationships. This way, the effect of growing populations of $M$. javanica (Treub) on the leaf area expansion rate (LAX) during the early development of cherry tomato access was evaluated. The negative effects of nematodes were expressed in early development of tomato plants. There was linear increase in population (FP) of M. javanica in all cherry tomato access as it was increased the initial level of nematode, resulting in reduction of linear TEAF. Thus any management practice that reduces the nematode population of soil during the growing season of tomatoes, will may favor the growth and development of plants and subsequently the production.
\end{abstract}

Keywords: Solanum licopersicum. Root-knot nematode. Leaf area. Damage

\footnotetext{
${ }^{1}$ Eng. Agr. Mestrando em Produção Vegetal pelo Programa de Pós-Graduação em Produção Vegetal (PPGPV) do Centro de Ciências Agrárias da Universidade Federal Espírito Santo (CCAUFES). Bolsista CAPES. E-mail: leonidas_agronomia@yahoo.com.br

${ }^{2}$ Eng . Agr. D. Sc. Professor Adjunto do Departamento de Produção Vegetal, CCAUFES - Centro de Ciências Agrárias da Universidade Federal do Espírito Santo/ Programa de Pós-Graduação em Produção Vegetal (PPGPV). E-mail: fabioramosalves@yahoo.com.br

${ }^{3}$ Eng . Agr. D. Sc. Professor Adjunto do Departamento de Produção Vegetal, CCAUFES - Centro de Ciências Agrárias da Universidade Federal do Espírito Santo/ Programa de Pós-Graduação em Produção Vegetal (PPGPV). Bolsista de Produtividade do CNPq. E-mail: wcintra@cca.ufes.br
} 


\section{INTRODUÇÃO}

O tomate (Solanum lycopersicum L.) está entre as mais importantes hortaliças cultivadas no Brasil e no mundo (FILGUEIRA, 2008). Em 2010, o Brasil produziu 3.691.316 toneladas de tomate em área de 60.772 ha (IBGE, 2011).

Entre os problemas que mais afetam a produção do tomateiro estão às doenças. Segundo Lopes e Santos (1994), mais de duzentas doenças podem limitar a produção dessa cultura. Dentre esses, os nematoides do gênero Meloidogyne (Goeldi) assumem considerável importância (CARVALHO et al., 1999).

Tomateiros infectados por nematoides, em especial $M$. javanica (Treub), apresentam porte reduzido, folhas reduzidas e amareladas, e intensa murcha nas horas mais quentes do dia, em conseqüência da abundante formação de galhas na raiz da planta prejudicando a absorção de água e nutrientes do solo (CHARCHAR; LOPES, 2005). Esses nematoides causam consideráveis prejuízos econômicos anuais no cultivo de tomate em todo o mundo, sendo que perdas de 14 a $44 \%$ podem ocorrer em plantas cultivadas sob ambiente protegido (CHARCHAR; ARAGÃO, 2005; CORTADA et al., 2010).

Os nematoides das galhas consistem em preocupação crescente para produtores de hortaliças. Técnicas de análise das relações planta/nematoide, e manejo populacional desses patógenos são necessários para que medidas de manejo sejam viabilizadas. No entanto, muitas práticas são apenas parcialmente eficazes, e assim, combinar métodos de manejo em uma análise sistêmica dessa relação representa um desafio (COLLANGE et al., 2011).

O acúmulo de matéria seca e o incremento da área foliar, quantificados em função do tempo, são utilizados na estimativa de vários índices fisiológicos relacionados às diferenças de desempenho entre cultivares ou diferentes genótipos da mesma espécie e das comunidades vegetais, nos diversos estudos ecofisiológicos e fitossanitários (BENINCASA, 2003; VALE et al., 2004). Alguns desses índices são: taxa de expansão da área foliar, taxa de crescimento absoluto e relativo, taxa de crescimento da cultura, índice de área foliar, razão de área foliar, entre outros.

O conhecimento dos índices de crescimento acima referidos é extremamente importante na interpretação das respostas das plantas ao meio aos inúmeros fatores nele presentes e/ou manejo das culturas. Não obstante, a existência de correlação entre esses índices e a interação patógeno-hospedeiro-ambiente, pode ser uma alternativa válida a fim de 
facilitar o desenvolvimento e direcionamento das práticas de manejo de fitopatógenos (Jesus Junior et al.; 2004; VALE et al., 2004).

Além disso, segundo Jesus Junior et al. (2004), estimativas confiáveis dos danos causados pelos patógenos são um pré-requisito para o desenvolvimento de qualquer programa bem sucedido de controle de doenças, independentemente do método a ser empregado. Portanto, a quantificação de danos é um ponto chave na definição de qualquer estratégia de manejo fitossanitário.

Neste contexto, objetivou-se com esse estudo quantificar o efeito do parasitismo de populações crescentes de $M$. javanica (Treub) sobre a expansão da área foliar na fase de desenvolvimento inicial de acessos de tomateiro cereja.

\section{MATERIAL E MÉTODO}

O experimento foi conduzido em casa de vegetação. Os tomateiros utilizados, denominados acessos 50, 78, 80 e 82, do tipo cereja, foram provenientes do Banco de Germoplasma da Universidade Estadual Norte Fluminense Darcy Ribeiro (UENF). A cultivar "Santa Clara" (SC) foi empregada como padrão de suscetibilidade ao nematoide (MOURA, 1997; ALVES; CAMPOS, 2001).

Foram empregadas as seguintes populações iniciais do nematoide (Pi): 0 (zero); 2.000; 4.000, 6.000 e 8.000 ovos + juvenis de segundo estádio (J2). O experimento foi conduzido em delineamento inteiramente casualizado em esquema fatorial 5 x 5 com oito repetições.

Para obtenção do inóculo, os nematoides foram multiplicados e mantidos em raízes de tomateiros cv. 'Santa Clara', cultivados em casa de vegetação, num substrato composto de solo e areia na proporção de 1:1 (v:v), previamente esterilizado em autoclave $\left(140^{\circ} \mathrm{C} / 1\right.$ hora em três dias consecutivos).

Para obtenção das mudas dos genótipos de tomateiros, as sementes foram semeadas em substrato organo mineral (Plantmax $®)$ contido em bandejas de isopor com 128 células. Vinte dias após a germinação, as mudas foram transferidas para sacolas plásticas (vasos) contendo $2.000 \mathrm{~cm}^{3}$ de substrato composto de solo e areia na proporção 2:1 (v:v) previamente esterilizado em autoclave, conforme descrição anterior. No ato de transplantio o solo foi infestado com as respectivas populações dos nematoides referidas acima. Cada unidade experimental foi composta por uma planta/vaso.

Adubações e controle de pragas e doenças da parte aérea foram realizados de acordo com as necessidades da cultura. As temperaturas máxima, mínima e média do ar durante o período experimental foi monitoradas com auxilio de termômetros instalados em uma estação 
meteorológica.

Quantificou-se a área foliar (AF) das plantas de tomateiro em quatro avaliações consecutivas, sendo a primeira no momento da infestação do solo com os nematoides e as demais respectivamente com intervalos de 10 dias entre avaliações. A AF foi determinada medindo-se a maior largura de todas as folhas fotossinteticamente ativas de cada planta. Esses dados foram transformados em área foliar através da equação proposta por Blanco; Folegatti (2003) (Equação 1):

Eq. 1

$$
L A=0,708 \cdot W^{2}-10,44 . W+83,4
$$

Em que: $\mathrm{LA}=$ área foliar $\left(\mathrm{cm}^{2}\right)$ e $\mathrm{W}=$ maior largura da folha $(\mathrm{cm})$.

Com os resultados da área foliar determinou-se a taxa de expansão da área foliar (TEAF, $\left.\mathrm{cm}^{2} \mathrm{dia}^{-1}\right)$ (Equação 2):

Eq. 2.

$$
\mathrm{TEAF}=\left(\mathrm{AF}_{\mathrm{x}}-\mathrm{AF}_{\mathrm{x}-1}\right) /\left(\mathrm{T}_{\mathrm{x}}-\mathrm{T}_{\mathrm{x}-1}\right)
$$

Em que: $\mathrm{AF}_{\mathrm{x}}$ e $\mathrm{AF}_{\mathrm{x}-1}=$ Área foliar $\left(\mathrm{cm}^{2}\right)$ em duas avaliações consecutivas; $\mathrm{e}_{\mathrm{x}}-\mathrm{T}_{\mathrm{x}-1}=$ intervalo de tempo entre duas avaliações.

Quarenta dias após a infestação do solo com os nematoides, extraiu-se o sistema radicular das plantas e este foi lavado dentro de um recipiente plástico com água. Para determinação da população final de nematoides por sistema radicular (PF) empregou-se o método de Hussey; Barker (1973), modificado por Boneti; Ferraz (1981).

Os dados foram submetidos à análise de variância e posteriormente, foram feitas análises de regressão. Utilizaram-se como critérios para a escolha do modelo o coeficiente de determinação, o quadrado médio do resíduo, o coeficiente de regressão, a significância do coeficiente de regressão $\left(ß_{1}\right)$, a análise do resíduo e adequação do modelo para descrição dos dados.

\section{RESULTADOS E DISCUSSÃO}

Houve aumento linear da PF de M. javanica (Treub) em todos os acessos de tomateiro cereja inoculados, à medida que se aumentou o nível do inóculo inicial do nematoide ( $\mathrm{p} \leq$ 0,05, Figura 01). 
Figura 01. População final de Meloidogyne javanica (Treub) em acessos de tomateiros cereja quarenta dias após a infestação do solo com populações iniciais de 2.000, 4.000, 6.000 ou 8.000 ovos + juvenis de segundo estádio (J2)/planta/vaso.

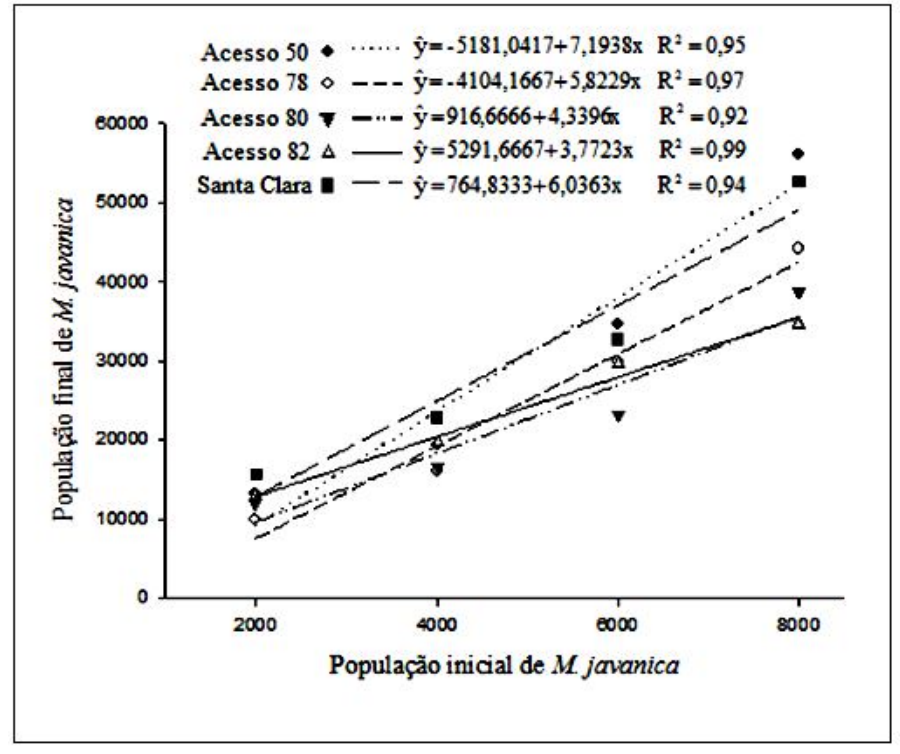

Fonte: Autores

Taylor e Sasser (1978) relataram que nematoides do gênero Meloidogyne se multiplicam em escala logarítmica, e com isso apresentam enorme potencial de reprodução e infestação do solo. Segundo esses autores, considerando-se uma única fêmea que produz em média 500 ovos e destes apenas 5\% sejam viáveis para originar novos indivíduos, em suas próximas quatro gerações serão originados 25, 625, 15.625 e 390.625 adultos, respectivamente.

Outro fato que deve ser considerado é o nível de resistência dos genótipos de tomateiro considerados neste estudo. Belan et al. (2009) avaliaram o nível de resistência desses acessos, e os classificaram, respectivamente, como: 50 - suscetível; 78, 80 e SC - altamente suscetíveis; e 82 - pouco resistente. Tais relatos vêm justificar o crescimento linear da população de nematoides parasitando as plantas dos referidos acessos de tomateiro.

As médias das temperaturas máxima, média e mínima do ar durante o período de condução do experimento foram, respectivamente, 29,36; 20,03 e 23,93 ${ }^{\circ} \mathrm{C}$, consideradas favoráveis ao desenvolvimento dos fitonematoides (CHARCHAR; LOPES, 2005).

A interação foi não significativa entre os fatores acessos de tomateiro e níveis de inóculo inicial de nematoides para a variável TEAF ( $p>0,05)$. Houve redução linear da TEAF à medida que aumentou o nível de inóculo inicial de $M$. javanica (Treub) $(\mathrm{p} \leq 0,01$, Figura 02). 
Figura 02. Taxa de expansão da área foliar (TEAF) de tomateiros cereja após infestação do solo com populações iniciais de 2.000, 4.000, 6.000 e 8.000 ovos + juvenis de segundo estádio (J2) de Meloidogyne javanica/planta/vaso. ** significativo a 1\% de probabilidade.

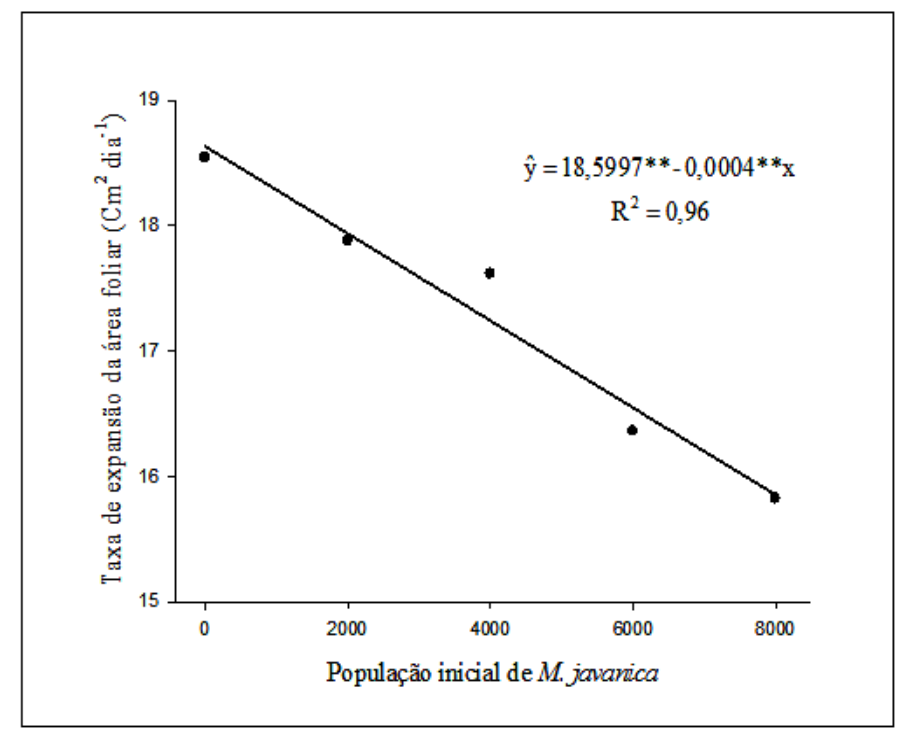

Fonte: Autores

Verifica-se que independente do nível populacional dos nematoides, houve redução na expansão foliar das plantas. Dentro do intervalo populacional estudado, a TEAF máxima $\left(18,6 \mathrm{~cm}^{2} \mathrm{dia}^{-1}\right)$ se deu com as plantas não parasitadas $(\mathrm{Pi}=0$ nematoides $)$ e esta foi decrescendo até valor mínimo $\left(15,4 \mathrm{~cm}^{2} \mathrm{dia}^{-1}\right)$ diante do parasitismo de 8000 indivíduos de $M$. javanica (Treub).

O crescimento e desenvolvimento das plantas de tomateiro dependem da partição dos assimilados de carbono entre fontes fotossinteticamente ativas (folhas) e drenos (folhas, raízes e frutos) (FARRAR; WILLIAMS, 1991). As atividades dessas fontes e drenos são reguladas por diferentes rotas metabólicas e, dessa forma, o crescimento, desenvolvimento e produtividade da cultura podem ser limitados tanto pela fonte quanto pelo dreno (HO, 1988). Neste caso, o parasitismo dos nematoides, em qualquer nível populacional, funcionou como um forte dreno de fotoassimilados, reduzindo a expansão foliar dos tomateiros.

Conforme verificado neste estudo, os efeitos negativos do parasitismo de nematoides em plantas de tomateiro cereja podem se manifestar na fase inicial de desenvolvimento das mesmas. Esse fato também fica evidente em culturas de ciclo curto como a alface (Lactuca sativa L.); Peixoto et al., 2011 verificaram que a medida que aumentou o nível de inóculo inicial de nematoides houve queda da área foliar (AF) e da razão de área foliar (RAF) das plantas de alface. Os autores hipotetizaram que o parasitismo de maiores populações de $M$. 
incognita (Kofoid \& White) (4000 e 6000 indivíduos/planta/vaso) causou queda na absorção de água e nutrientes pelas raízes, diminuindo a área foliar das plantas.

Resultados semelhantes aos desse estudo já foram descritos para outras culturas e gêneros de nematoides. Ferraz (1995) avaliou as cultivares de soja: Andrews, Invicta e Ocepar-14 mediante inoculação de diferentes níveis populacionais iniciais de Pratylenchus brachyurus (Godfrey) em casa de vegetação e observou redução na taxa de crescimento das três cultivares de soja, principalmente com os níveis de 1000 e 5000 espécimes/planta/vaso.

Fortnum et al. (1991) inocularam plantas de tomateiro cv. Rutgers com populações iniciais de $0,1,10,50,100$, e 200 (x 1.000) ovos de M. incognita (Kofoid \& White) por planta e observaram redução da área foliar como o aumento da Pi. Ensaios realizados por Inomoto et al. (2001) utilizando diferentes populações de $P$. brachyurus em duas cultivares de algodoeiro (IAC 20 e IAC 22) demonstraram que a altura final das plantas independe da densidade populacional do inóculo inicial do nematoide e densidades populacionais mais altas, acima de 9000 nematoides/planta, afetaram ligeiramente a massa fresca das raízes e a massa seca da parte aérea.

Estimativas confiáveis dos danos causados pelos patógenos às culturas são indispensáveis em programas de manejo fitossanitário. Com base nos resultados deste estudo, verifica-se que práticas de manejo que reduzam a população de nematoides do solo durante a fase vegetativa dos tomateiros poderão favorecer o crescimento e desenvolvimento das plantas e consequente produção de frutos.

O presente estudo vem orientar pesquisas futuras sobre quantificação dos danos provocados pelos nematoides sobre outras características de crescimento e produção das culturas. Diante da afirmativa da redução da TEAF na fase vegetativa de desenvolvimento de tomateiros, é necessário verificar seus reflexos, correlacionar e quantificar esses danos na fase produtiva da cultura.

É importante destacar, que diferentes genótipos de tomateiros precisam ser testados. Outro fato é que diferentes isolados do nematoide podem provocar efeitos diferenciados em cada genótipo em suas diferentes fases de desenvolvimento, principalmente quando pesquisas são feitas em regiões com condições edafoclimáticas distintas.

\section{CONCLUSÃO}

Os efeitos negativos do parasitismo de nematoides se manifestaram na fase inicial de desenvolvimento dos tomateiros evidenciados pela redução da TEAF. 
O aumento do nível de inoculo inicial de $M$. javanica (Treub) causa uma redução linear na taxa de expansão foliar de tomateiros cereja na fase inicial de desenvolvimento das plantas.

\section{REFERÊNCIAS}

ALVES, F.R.; CAMPOS, V. Efeito do aquecimento do solo na resistência de plantas a Meloidogyne javanica e M. incognita raça 3. Nematologia Brasileira, v. 25, n. 2, p. 153-162, 2001.

BELAN, L. L. et al. Screening of cherry tomato genotypes for resistance to Meloidogyne incognita and M. javanica. Nematologia Brasileira. v. 33, p. 256 - 259, 2009.

BENINCASA, M.M.P. Análise de crescimento de plantas: noções básicas. Jaboticabal: FUNEP, 2003. 42 p.

BLANCO, F.F.; FOLEGATTI, M.V. A new method for estimating the leaf area index of cucumber and tomato plants. Horticultura Brasileira, v. 21, n. 4, p. 666-669, 2003.

BONETI, J.I.; FERRAZ, S. Modificações do método de Hussey \& Barker para extração de ovos de Meloidogyne exigua em raízes de cafeeiro. In: CONGRESSO DA SOCIEDADE BRASILEIRA DE FITOPATOLOGIA, XIV, Porto Alegre, RS. Fitopatologia Brasileira, p.553, 1981.

CARVALHO, J.W.A. et al. Obtenção de linhagens de tomateiro de crescimento determinado com resistência múltipla a nematoides de galhas e a tospovírus. Ciência e Agrotecnologia, v. 23, n. 3, p. 593-607, 1999.

CHARCHAR, J.M.; ARAGÃO, F.A.S. Reprodução de Meloidogyne spp. em cultivares de tomate e pepino sob estufa plástica e campo. Nematologia Brasileira, v. 29, n. 2, p. 243-249. 2005.

CHARCHAR, J.M.; LOPES, C.A. Nematoides. In: LOPES, C.A.; ÁVILA, A.C. Doenças do tomateiro. Empresa Brasileira de Pesquisa Agropecuária, EMBRAPA Hortaliças, Brasília, DF, 2005. p. 97-100.

COLLANGE, B. et al. Root-knot nematode (Meloidogyne) management in vegetable crop production: The challenge of an agronomic system analysis. Crop Protection, v. 30, n. 10, p. 1251-1262, 2011.

CORTADA, L. et al. Patrones de tomate resistentes a Meloidogyne: Variabilidad de la respuesta de resistencia en función de la población del nematodo. Horticultura Global, v. 288, p. 40-45. 2010.

FARRAR J.F.; WILLIAMS J.H.H. Control of the rate of respiration in roots: compartmentation, demand, and the supply of substrate. In: EMMS, M. (ed.).

Compartmentation of Plant Metabolism in Non-Photossinthetic Tissues. Cambridge University Press, Canbridge, UK. p. 167-188. 1991. 
FERRAZ, L.C.C.B. Patogenicidade de Pratylenchus brachyurus a três cultivares de soja. Nematologia Brasileira, Brasília, v. 19, n. 1, 1995, p. 01-08.

FILGUEIRA F. Novo Manual de Olericultura: Agrotecnologia moderna na produção e comercialização de hortaliças. Viçosa: UFV, 2008. 421p.

FORTNUM, B.A. et al. Biomass Partitioning in Tomato Plants Infected with Meloidogyne incognita. Journal of Nematology, v. 23, n. 3, p. 291-297, 1991.

HO, L.C. Metabolism and compartimentation of import sugars in sink organs in relation to sink strength. Annual Review of plant Physiology and Plant Molecular Biology, v. 39, p. 355-378, 1988.

IBGE - Instituto Brasileiro de Geografia e Estatística. Levantamento Sistemático da Produção. Disponível em:

<http://www.ibge.gov.br/home/estatistica/indicadores/agropecuaria/lspa/default.shtm>. Acesso em: 01 ago. 2011.

INOMOTO, M.M. et al. Effect of population densities of Pratylenchus brachyurus on the growth of cotton plants. Fitopatologia Brasileira, Fortaleza, v. 26, n. 2, p. 192-196, 2001.

JESUS JUNIOR, W.C. et al. Tomada de decisão no manejo de doenças de plantas. In: VALE, F.X.R., JESUS JUNIOR, W.C.; ZAMBOLIM, L. (Eds.). Epidemiologia aplicada ao manejo de doenças de plantas. Perfil Editora, 2004. 531p.

LOPES, C.A.; SANTOS, J.R.M. Doenças do Tomateiro. EMBRAPA-CNPH, Brasília, 1994. $61 \mathrm{p}$.

MOURA, R.M. O gênero Meloidogyne e a meloidoginose. Parte II. In: FERNANDES, J.M.; PRESTES, A.M.; PICININI, E.C. (Eds). Revisão Anual de Patologia de Plantas, v. 5, p. 281-315, 1997.

PEIXOTO, J.R. Melhoramento de pimentão (Capsicum annuum L.) visando a resistência aos nematoides do gênero Meloidogyne spp. 1995. 103p. Tese (Doutorado em Fitotecnia) Universidade Federal de Lavras, Lavras - MG, 1995.

PEIXOTO, L.A. et al. Quantificação de danos em alface causados por diferentes níveis de Meloidogyne incognita em diferentes tipos de solo. Enciclopédia biosfera, v. 7, n. 12, p. 112, 2011.

TAYLOR, A.L.; SASSER, J.N. Biology, identification and control of root-knot nematodes (Meloidogyne ssp.). Raleigh: North Carolina State University, 1978. 111p.

VALE, F.X.R. et al. de. Quantificação de doenças e do crescimento do hospedeiro. In: VALE, F.X.R., JESUS JUNIOR, W.C.; ZAMBOLIM, L. (Eds.) Epidemiologia aplicada ao manejo de doenças de plantas. Perfil Editora, 2004. 531p. 
